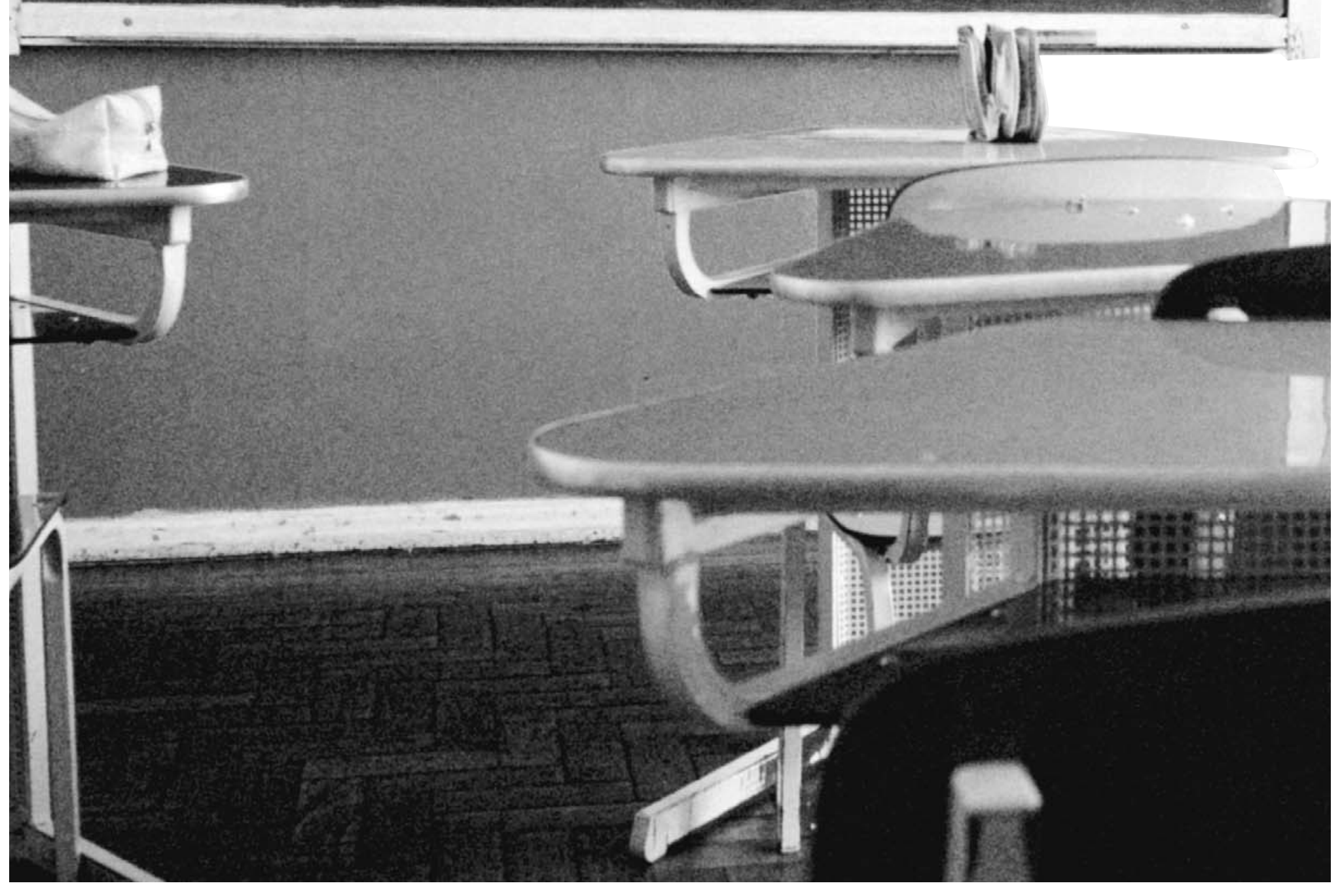




\section{Conhecer as mil faces da escola para ampliar o direito de aprender}

\begin{abstract}
Ao identificar boas práticas relacionadas com aspectos tangíveis e intangíveis das escolas, o estudo fortaleceu nossa visão de que escolas têm corpo e alma.

Inseparáveis e complementares, corpo e alma são fonte geradora de aprendizagens. Mas é a alma da escola que faz com que todos e cada um dos integrantes da comunidade escolar vivenciem a bela experiência humana de aprender um pouco mais a cada dia.
\end{abstract}

stas são as palavras de encerramento do Aprova Brasil: o direito de aprender, uma publicação lançada em dezembro de 2006 pelo Fundo das Nações Unidas para a Infância - Unicef (sigla em inglês do United Nations Children's Fund, redução do nome original United Nations International Children's Emergency Fund) e pelo Ministério da Educação e Cultura - MEC, contendo os resultados de um estudo realizado em 33 escolas públicas, situadas em 14 Estados e no Distrito Federal. ${ }^{1}$

A idéia dessa iniciativa conjunta do Ministério da Educação e do Unicef tem origem nos resultados da Prova Brasil; e sua inspiração e motivação vêm do compromisso com a garantia do Direito de Aprender de todas as crianças e jovens brasileiros.

\footnotetext{
* MARIA de SAlete silva é arquiteta, consultora de educação do Unicef e coordenou o estudo Aprova Brasil: o direito de aprender.
} 


\section{A Prova Brasil}

\section{Realizada pelo Instituto Nacional de Estudos e Pesqui-} sas Educacionais Anísio Teixeira - INEP, em 2005, a Prova Brasil foi a primeira avaliação em caráter universal efetuada nas escolas públicas urbanas que oferecem a $1^{\underline{a}}$ fase e/ou a $2^{\underline{a}}$ fase do ensino fundamental, com mais de 30 alunos na série avaliada. Foram aplicadas provas aos alunos de $4^{\underline{a}}$ e $8^{\underline{a}}$ série com o objetivo de avaliar seu desempenho em Língua Portuguesa (leitura) e Matemática. No total, fizeram a prova 3.306.378 alunos de 40.290 escolas, localizadas em 5.398 municípios de todas as regiões brasileiras.

Esse tipo de avaliação permitiu a divulgação dos resultados por unidade escolar. Conhecendo os resultados obtidos pelas escolas na Prova Brasil, gestores, dirigentes escolares e a sociedade em geral podem se mobilizar para buscar melhorias no ensino, tomando como base o desempenho das escolas do seu estado, seu município, sua rede escolar ou demais escolas de seu bairro, e cobrar mais responsabilidade das escolas, professores e dirigentes em relação ao desempenho dos seus alunos. ${ }^{2}$

\section{Unicef e 0 direito de aprender}

A base para a cooperação do Unicef e das demais agências do sistema ONU, no âmbito do Marco de Assistência das Nações Unidas para o Desenvolvimento (Undaf), é a criação e o desenvolvimento das capacidades dos detentores dos direitos e dos responsáveis pela garantia desses direitos, com os quais os países-membros comprometeram-se ao ratificar a Convenção dos Direitos da Criança e, no caso brasileiro, ao aprovar o Estatuto da Criança e do Adolescente.

O Programa de País do Unicef, para o período 20072011,3 pretende apoiar o Brasil no cumprimento de suas obrigações de garantir os direitos de cada criança e cada adolescente, desenvolvendo cinco Programas, denominados:

- Sobreviver e se Desenvolver;

- Aprender;

- Proteger-se do HIV/AIDS;

- Crescer sem Violência; e

- Ser Prioridade nas Políticas e Orçamento Públicos. As perspectivas de eqüidade de raça/etnia e gênero e de participação dos adolescentes permeiam todos

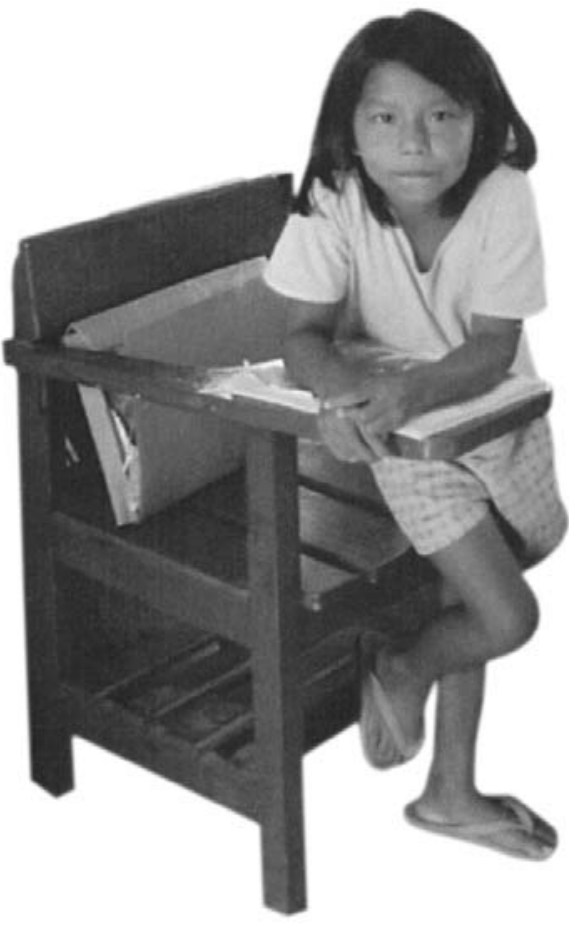

os programas. O foco da atuação do Unicef concentrarse-á nas áreas onde se encontram as crianças mais vulneráveis e excluídas: o semi-árido brasileiro, a Amazônia e as comunidades populares de grandes centros urbanos.

O Brasil quase atingiu o Segundo Objetivo do Milênio - Ensino Fundamental Universal - com 98\% das crianças, de sete a 14 anos, matriculadas. Esses 2\% significam ainda que cerca de 800 mil crianças nessa faixa etária permanecem fora da escola, das quais, 500 mil são negras. A situação das crianças indígenas expressa ainda uma maior iniqüidade: cerca de $21,5 \%$ delas, de sete a 14 anos, estão fora da escola.

Persistem também grandes desigualdades regionais: enquanto no Norte e Nordeste somente $40 \%$ das crianças terminam o ensino fundamental, no Sul e no Sudeste, esta proporção sobe para $70 \% .^{4}$

O Brasil tem 21 milhões de adolescentes entre 12 e 18 anos, representando $11 \%$ da população. Mais de 3,5 milhões deles estão fora da escola. De cada 100 estudantes que entram no ensino fundamental, 82 concluem a $5^{\underline{a}}$ série, 59 terminam a $8^{\underline{a}}$ série e apenas 40 , o ensino médio. ${ }^{5}$

Diante dessa situação marcada pela desigualdade e iniqüidade no acesso e na qualidade da educação, o Programa de País do Unicef concentra o foco de sua atuação na busca de educação de qualidade para todas as crianças e adolescentes de até 17 anos e na garantia de acesso de 800 mil crianças de sete a 14 anos que estão atualmente fora da escola, assim como o in- 
gresso de oito milhões de adolescentes de baixa renda e baixa escolaridade no ensino médio.

\section{A indissociabilidade entre educação de qualidade e aprendizagem}

Dirigir para o aprender o foco da mobilização em torno da educação de qualidade tem sido cada vez mais freqüente no Brasil. Dois exemplos de grandes mobilizações da sociedade civil demonstram esse movimento. A Campanha Nacional pelo Direito à Educação, que tem a participação de diversas organizações sociais, estabelece, como foco de sua ação, a qualidade da educação para que o aprendizado seja efetivo. 0 Compromisso Todos pela Educação, envolvendo setores da sociedade civil, empresas e governo, estabeleceu cinco metas para 2022 (bicentenário da Independência), todas elas fortemente relacionadas com as possibilidades de aprendizagem de meninos e meninas nas escolas públicas do país.

Refletir sobre a aprendizagem como resultado de uma educação de qualidade envolve os aspectos relacionados com os tempos, práticas e conteúdos da escola. Significa também pensar em educação integral, em articulações sistêmicas entre políticas públicas e programas de atendimento a crianças, famílias e comunidades. Uma educação de qualidade deve garantir o direito de aprender.

\section{Um universo a ser observado...}

Os resultados da Prova Brasil abriram um rico campo de observação sobre situações que podem levar à aprendizagem da leitura, dos cálculos e raciocínio matemáticos em escolas públicas de ensino fundamental.

$O$ estudo realizado pelo MEC e Unicef partiu de uma idéia-chave: as respostas para as indagações referentes à aprendizagem das crianças podem estar nas próprias escolas. Mais do que isso, elas devem surgir de observações e reflexões com participação ativa dos protagonistas do fazer escolar.

Quais as características das escolas nas quais os alunos alcançaram bom desempenho na Prova Brasil? Que escolas deveriam ser observadas e estudadas?

Para identificar as diversas dimensões da gestão, organização e funcionamento de escolas que podem ter contribuído para a melhor aprendizagem dos alunos, foram selecionadas 36 escolas das cinco regiões geográfi- cas brasileiras, segundo critérios socioeconômicos e de desempenho na Prova Brasil.

As escolas foram escolhidas devido a seus resultados na avaliação. Não deixaram de ser também consideradas as informações sobre a situação socioeconômica dos alunos que participaram da Prova e dos municípios em que elas se localizam.

Com isso, foi possível comparar as escolas, não só observando a nota média obtida por seus alunos, como também o quanto cada uma delas pode ter contribuído efetivamente para o seu desempenho na prova. É o que se chamou de IEE - Índice de Efeito Escola, que mede o impacto que a instituição tem na vida e no aprendizado da criança. Por isso, as escolas visitadas não são as que obtiveram melhores notas, em valores absolutos, e sim aquelas com o mais alto "efeito-escola". Elas situam-se em municípios ou bairros onde moram famílias de baixa renda, portanto, seus alunos apresentam alta vulnerabilidade para a exclusão social e, mesmo assim, eles aprendem.

Chegou-se então a um grupo de escolas que apresentou resultados de desempenho na Prova Brasil sempre acima da média nacional e superiores também em relação às escolas da mesma região e com características semelhantes, segundo os critérios utilizados pelo Unicef e MEC.

\section{As escolas analisadas}

Foram visitadas e analisadas 33 escolas de ensino fundamental, sendo 20 municipais e 13 estaduais, em $32 \mathrm{mu}$ nicípios de 14 estados e do Distrito Federal.

\begin{tabular}{lc} 
ESTADOS E ESCOLAS & \\
\hline UNIDADE FEDERATIVA & NÚMERO DE ESCOLAS \\
Amazonas & 4 \\
Bahia & 2 \\
Ceará & 2 \\
Distrito Federal & 1 \\
Goiás & 1 \\
Maranhão & 1 \\
Minas Gerais & 4 \\
Mato Grosso do Sul & 2 \\
Pará & 1 \\
Piauí & 1 \\
Paraná & 3 \\
Rio de Janeiro & 6 \\
Rio Grande do Sul & 1 \\
São Paulo & 3 \\
Tocantins & 1
\end{tabular}




\section{Princípios norteadores do Projeto}

\section{Alguns princípios orientaram a direção do olhar so-} bre as escolas, procurando-se identificar em que medida elas estão garantindo os direitos da criança, em especial o direito de aprender. São eles:

- o direito à educação é direito de todas e de cada uma das crianças e adolescentes;

- o direito à educação deve observar os princípios da universalidade, progressividade, indivisibilidade e interdependência, exigibilidade e participação;

- todas as crianças e adolescentes têm direito à educação de qualidade, independente de origem étnica, racial, social ou geográfica;

- a escola é parte integrante do sistema de garantia de direitos das crianças e adolescentes;

- a escola é lugar privilegiado para assegurar a cada criança e adolescente o direito de aprender;

- a gestão escolar deve ser democrática, garantindo a alunos, professores, funcionários, famílias e comunidade o direito à participação.

\section{Aprova Brasil: uma experiência de observação participativa}

Com um olhar orientado pelo marco de direitos, 0 projeto buscou identificar que aspectos podem ter contribuído para o bom desempenho das escolas, o que certamente não se deve a um único fator ou dimensão da gestão escolar. Cada escola tem história, rotinas, projetos e formas de trabalho construídas ao lo ngo do tempo. As escolas visitadas situam-se em municípios e comunidades com características culturais, sociais e econômicas diferenciadas, e pertencem a redes também diversas. Portanto, para anunciar os resultados da pesquisa como "boas práticas de educação pública”, foi preciso ir além da identificação de um ou outro fator, e descrever, ainda que sucintamente, os processos e atividades por meio dos quais essas práticas se efetivam e o contexto em que elas se inserem.

O estudo lançou mão de uma metodologia denominada “pesquisa rápida” (rapid assesment), que parte da investigação de um núcleo central de interesse - no caso, as escolas selecionadas - para levantar elementos que permitam identificar questões relevantes do universo pesquisado.
Para realizar a pesquisa em campo, foram selecionados 12 pesquisadores, por meio de edital público. 0 grupo tinha formação e experiência bastante diversificadas em pesquisa e avaliação. Os pesquisadores foram incentivados e capacitados, a fim de realizar uma análise a mais aberta e ampla possível, estarem totalmente disponíveis para escutar e observar, além de, por meio de muita determinação e disciplina, registrar cada momento da visita. Todo o trabalho nas escolas foi baseado em um "Caderno de Campo", organizado de maneira a orientar os contatos e possibilitar o registro das observações, conversas, entrevistas e reuniões.

Nos dois dias em que passaram em cada escola, os pesquisadores procuraram conversar com todos os atores que poderiam contribuir - e como contribuíram! para o entendimento das razões do bom desempenho das crianças na Prova Brasil. Para entender o processo de aprendizagem dos alunos, buscava-se a visão mais ampla e multifacetada possível.

A inspiração para essa postura aberta e para a necessidade de captar a diversidade das faces e dimensões da escola veio de um poema de Paulo Leminsky:

\section{Quando eu vi você \\ Tive uma idéia brilhante \\ Foi como se eu olhasse \\ De dentro de um diamante \\ E meu olho ganhasse \\ Mil faces num só instante.}

Além de observar estas “mil faces”, era preciso ouvir cada uma delas. E essa escuta foi inspirada em um texto de Leonardo Boff:

Ler significa reler e compreender, interpretar: cada um lê com os olhos que tem. E interpreta a partir de onde os pés pisam.

Todo ponto de vista é a vista de um ponto. Para entender como alguém lê, é necessário saber como são seus olhos e qual é a sua visão de mundo. Isso faz da leitura sempre uma releitura.

A cabeça pensa a partir de onde os pés pisam. Para compreender é essencial conhecer o lugar social de quem olha. Vale dizer: como alguém vive, com quem convive, que experiência tem, em que trabalha, que desejos alimenta, como assume os dramas da vida e da morte e que esperanças o animam. Isso faz da compreensão sempre uma interpretação. ${ }^{8}$ 
A maioria dos que

participaram das

entrevistas, reuniões $e$

conversas atribuiu o bom

desempenho das crianças

aos professores, aos

próprios alunos, às práticas

pedagógicas desenvolvidas

e à participação da

comunidade.

Os atores, com os quais obrigatoriamente o pesquisador deveria fazer contato, seja por meio de observação de práticas, entrevistas, reuniões ou mesmo de conversas mais informais, foram: a direção, a coordenação pedagógica, os professores, os alunos, suas famílias, funcionários e membros do Conselho Escolar. Para complementar, eventualmente foram ouvidos parceiros externos da escola, dirigentes municipais de educação, membros da comunidade do entorno da escola.

Todo o processo de escuta tinha, como coluna vertebral, uma questão central, que deveria ser respondida por todos os atores:

Esta escola teve um desempenho na Prova Brasil - Matemática e Língua Portuguesa na $4^{\text {a }}$ e/ou $8^{\underline{a}}$ série - acima da média das escolas públicas brasileiras.

A que pode ser atribuído esse resultado?

O Caderno de Campo, guia desse processo de observação e escuta, foi elaborado de maneira simples e adequada à metodologia de pesquisa rápida, e estava dividido em três blocos:

- quadros com registro de informações quantitativas sobre o município e a escola;

- roteiros para observação, entrevistas, conversas, reuniões, com orientações de caráter geral e indicações específicas para cada um dos atores participantes;

- formulários para registro de informações qualitativas do pesquisador.

0 roteiro de observação e contato com os atores foi construído a partir da publicação Indicadores de Qualidade 9 na Educação, cujo objetivo é incentivar a comunidade escolar a avaliar a qualidade da educação em sua escola. Nela, são propostas sete dimensões de avaliação que serviram de base para a construção do Caderno de Campo:

- ambiente educativo;

- prática pedagógica;

- avaliação;

- gestão escolar democrática;

- formação e condições de trabalho dos profissionais da escola;

- ambiente físico escolar;

- acesso, sucesso e permanência na escola.

Durante as visitas às escolas, os alunos, crianças e adolescentes, tiveram um papel central: eles conduziram os pesquisadores, mostraram e opinaram sobre os espaços, contaram sobre sua percepção das aulas e atividades desenvolvidas, seus processos de aprendizado, as relações entre os atores, os resultados da Prova Brasil.

Por que a nossa escola foi bem no Prova Brasil:

- $\quad$ por causa do bom desempenho dos alunos;

- $\quad$ porque tem professores inteligentes;

- $\quad$ porque as cantineiras são boazinhas e fazem uma merenda gostosa;

- $\quad$ porque os professores são criativos e trazem coisas novas, como músicas, livros, pesquisas, e não fica aquela aula cansativa;

- $\quad$ porque temos muitas tarefas na sala de aula;

- $\quad$ porque a avaliação é por trimestre e estimula o aluno a estudar o ano todo;

- $\quad$ porque a supervisora é maravilhosa, uma fada.

Alunos da 8 ${ }^{a}$ SÉRIE dA EsCola Municipal Desembargador APRíGIO RIBEIRo de OLIVEIRA, SÃo BRÁS do SUAÇUÍ, MG.

\section{A percepção dos atores sobre as razões do bom desempenho das crianças}

As respostas à questão central da pesquisa revelam a percepção dos atores em relação às causas do bom desempenho das crianças de cada escola visitada. A maioria dos que participaram das entrevistas, reuniões e conversas atribuiu o bom desempenho das crianças aos professores, aos próprios alunos, às práticas pedagógicas desenvolvidas e à participação da comunidade.

- $O$ professor: atitudes, capacidades, formação.

Empenho, competência, capacitação, interesse, dedicação, abertura para criar atividades e estimular os 
alunos. Estas foram as características destacadas por todos os que consideraram o professor como o principal responsável pelo bom desempenho das crianças.

Os professores são criativos e trazem coisas novas, como músicas, livros, pesquisas, e não fica aquela aula cansativa.

Alunos da 8 a SÉRIE da Escola Municipal DeSEMbargador Aprígio Ribeiro de Oliveira, São Braz do Suaçuí, Mg.

\section{- Alunos: sujeitos ativos da aprendizagem}

A atitude dos participantes em relação aos alunos é francamente positiva. Eles são parte ativa do sucesso das escolas e não a razão de seus problemas, posição muitas vezes adotada por alguns setores da comunidade escolar. Essa atitude repercute na auto-estima e auto-imagem dos alunos que, em muitas das escolas pesquisadas, afirmam que confiam nas suas capacidades, consideram-se inteligentes e têm facilidade para aprender:

A prova foi fácil e nós somos inteligentes.

Alunos da Escola Estadual Coronel Antônio Trindade, Aquidauana, MS.

\section{- Práticas pedagógicas: inovações, interação com outros ambientes.}

As atividades pedagógicas desenvolvidas nas salas de aula ou em outros ambientes são consideradas um dos fatores mais importantes para o bom desempenho das crianças, embora muitas dessas atividades e propostas não cheguem a configurar um projeto pedagógico formal e estruturado. A variedade de recursos utilizados, os tempos dedicados à aprendizagem - no turno de estudo e em atividades complementares no turno oposto - a mobilização e a participação de alunos, e até mesmo das famílias, nos projetos, a quebra da rotina de sala de aula ou da forma de organizar os espaços e o mobiliário escolar foram citados por muitos dos participantes da pesquisa.

Além desses aspectos, muitos atores se referiram à disciplina e à organização da escola como elementos que impulsionam e valorizam a aprendizagem:

Aqui os alunos, pais e professores são cobrados e cobram com muito rigor e disciplina.

DIRETORA DE UMA DAS ESCOLAS VISITADAS.

- Famílias e comunidade: parte do cotidiano da escola Em muitas das escolas analisadas, a participação das famílias e da comunidade foi considerada um fator importante para o bom desempenho escolar das crianças. Pelos depoimentos, foi possível verificar que essa participação acontece de três formas:

- na gestão da escola;

- no envolvimento e presença dos pais de alunos;

- nas parcerias firmadas com instituições, como empresas, organizações sociais, associações de moradores, universidades e ONGs, entre outras.

Entendida como um fator que interfere positivamente na aprendizagem, a gestão democrática e participativa aponta para a ampliação do processo educativo que se estende para além da estrita relação educador-educando, envolvendo outros territórios, o contexto social e comunitário e outros tempos, além do tempo escolar.

Sei que a escola tirou o "primeiro lugar" na Prova Brasil. Tem um outdoor aqui na frente da escola. Acho que isso foi possível pelo jeito que os professores ensinam as crianças. Eles sabem ensinar e os alunos têm mais liberdade de perguntar quando têm dúvidas.

PAI DE ALUNO NA ESCOLA

Professor Guiomar Gonçalves neves, Trajano de Moraes, RJ.

\section{As boas práticas das escolas: inspiração para melhorar a aprendizagem}

No estudo Aprova Brasil, o direito de aprender, a expressão "boas práticas" significa procedimentos, atividades, experiências e ações que apresentam resultados positivos na aprendizagem de crianças e adolescentes, alunos das escolas analisadas.

A sistematização de práticas, apresentada na publicação, foi feita a partir da análise da coerência pedagógica, da adequação aos princípios norteadores do estudo, da sintonia com a abordagem dos direitos das crianças e adolescentes, da sua relação com o dia-adia da escola e do potencial de disseminação para outras escolas.

A metodologia e o desenvolvimento do estudo não permitem atribuir o bom desempenho dos alunos das escolas analisadas exclusivamente às práticas relatadas. Mas é possível destacá-las como relevantes e significativas para a escola, para os atores que participaram da pesquisa e, principalmente, para os resultados na aprendizagem das crianças.

O estudo as apresenta como sugestões ou boas 
idéias, não como receitas ou fórmulas prontas. Elas terão cumprido um importante papel se servirem de inspiração para políticas, programas, diretrizes ou projetos que possam contribuir para a melhoria da qualidade da aprendizagem de crianças e adolescentes, alunos de escolas públicas brasileiras.

\section{Dimensões do aprender: os achados do Aprova Brasil}

\section{Complementando a resposta à questão central, todos} os participantes do estudo - direção, professores, coordenadores, alunos, famílias, funcionários e membros da comunidade - foram solicitados a descrever uma ou mais práticas desenvolvidas na escola que contribuíam efetivamente para a aprendizagem das crianças.

Ao analisar e sistematizar as boas práticas apontadas pelos atores-participantes nas 33 escolas pesquisadas, foi possível agrupá-las, por similaridade, em cinco blocos, chamados de "dimensões do aprender".

\section{Dimensão 1: práticas pedagógicas, a caminho da educação integral.}

0 maior número de atividades citadas refere-se a práticas pedagógicas, envolvendo estratégias de trabalho dos educadores, projetos de ensino, uso e produção de materiais didáticos, processos de avaliação e recuperação da aprendizagem dos alunos.

Verificou-se que elas não nascem no vazio ou da intenção ou desejo isolados de um ou mais setores da comunidade escolar. Elas são fruto de uma conjunção de condições objetivas e do compromisso da equipe e da comunidade escolar com a aprendizagem dos alunos. Sua força e efetividade dependem de uma atitude atenta e cuidadosa de todos no momento de planejar, realizar e avaliar cada passo. Essas práticas não são eternas nem imutáveis.

A publicação apresenta-as agrupadas em sete grupos temáticos, seja por características de gestão, por forma de desenvolvimento ou tipos de atividades desenvolvidas. São eles:

\section{- Trabalho coletivo, em equipe, compartilhado, co- ordenado.}

Muitas das escolas estudadas desenvolvem experiências de planejamento coletivo, de encontros e centros de estudo, de articulação, intercâmbio de práticas e conhecimento entre educadores.

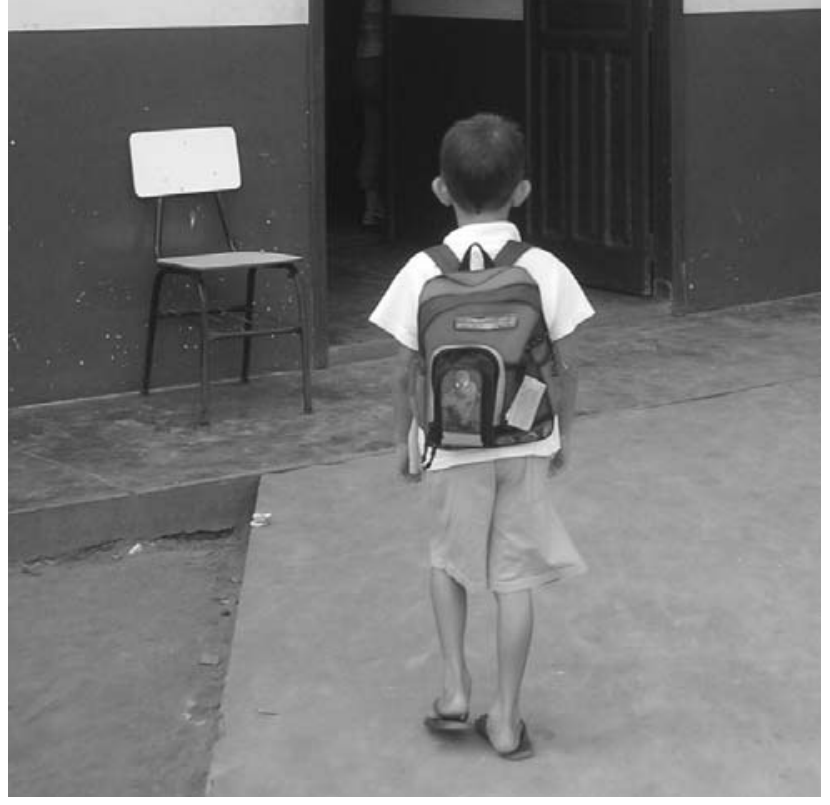

\section{- Projetos de ensino}

Todas as escolas analisadas desenvolvem projetos de ensino próprios, nas salas de aula, em outros espaços da escola ou externos. Muitos envolvem mais de um professor ou mais de uma turma e disciplinas diferentes. Tomam a forma de oficinas de teatro ou música, de produção de textos, de programas de rádio, de informática.

Alguns acontecem no turno oposto ao de aulas regulares, outros são apresentados para a comunidade como eventos socioeducativos.

Os projetos descritos apresentam forte potencial para mobilizar a participação dos alunos, propiciar a interdisciplinaridade, abrir portas para a integração com a comunidade. Mais do que isso, interferem positivamente na mudança dos processos de avaliação do desempenho dos alunos.

Os projetos são uma inovação, mas não fazemos nada mirabolante, trabalha-se com aquilo que se tem. A maior dificuldade é colocar os projetos no papel e registrar cada passo e os resultados, pois falta hábito ao professor. Mas os projetos são sempre um trabalho conjunto, interdisciplinar, e têm ajudado na melhoria do ensino e aprendizagem.

Professoras de Matemática e Português da Escola Estadual CRISTÓforo MYskiv, PRudentópolis, PR.

\section{- Inovações na organização da escola}

Aqui estão algumas experiências de mudança na organização espacial das salas de aula e de outros espaços educativos, no aumento e na forma de distribuição dos tempos escolares, na integração entre disciplinas. 


\section{- Ensino contextualizado}

A forma, o conteúdo e o material didático utilizado nas atividades de ensino consideram a realidade dos alunos e de sua comunidade. Em muitas das escolas, há materiais construídos pela própria equipe, muitas vezes com participação dos alunos. Todas utilizam livros didáticos, mas, na maioria delas, o projeto da própria escola determina a ordem dos temas, o momento e a forma de sua utilização pelos alunos.

\section{- Novas formas de avaliação e acompanhamento da aprendizagem}

Experiências de programas de recuperação paralela ao período de aulas, aulas de reforço, atenção individual. Algumas dessas atividades são realizadas com parceiros externos.

\section{- Atividades externas com alunos}

Programas que abrem as portas da escola, permitindo que as crianças conheçam sua cidade e outras escolas. Idas ao cinema e ao teatro, atividades de educação ambiental e, até mesmo, viagens para outros municípios são relatadas neste bloco.

\section{- Incentivo à prática de jogos e esportes}

Em muitas escolas, as crianças jogam xadrez, damas, competem em torneios e campeonatos de esportes coletivos, muitos deles com a participação da comunidade.

\section{Dimensão 2: a importância do professor}

\section{Em todas as escolas, houve relatos de boas práticas re-} lacionadas ao professor, sejam aquelas voltadas para sua

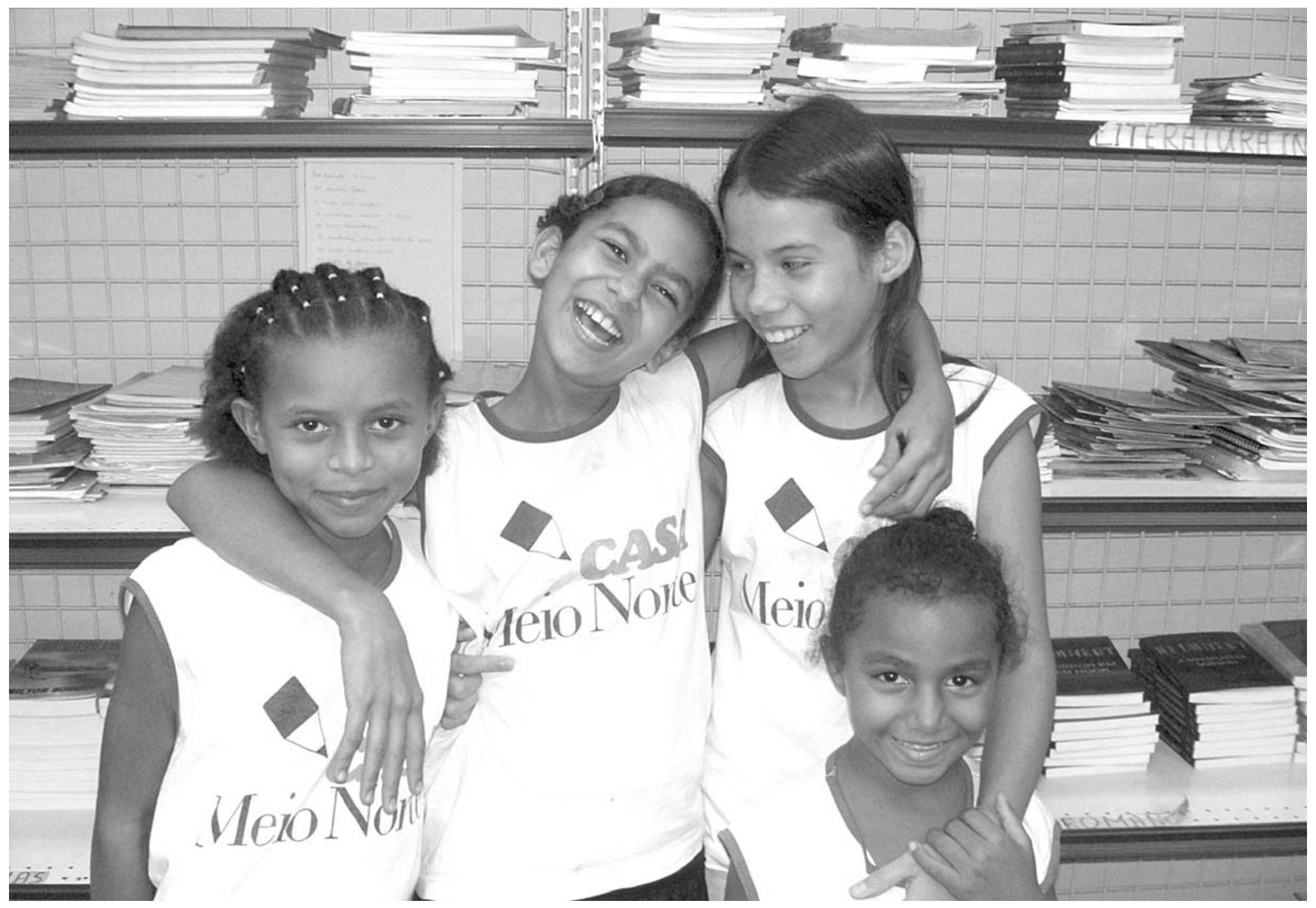


formação inicial e continuada, sejam as que relatam experiências que comprovam seu compromisso, entusiasmo, dedicação e criatividade.

As boas práticas relatadas são agrupadas em dois blocos: Formação e Valorização. No primeiro, são relatadas experiências de formação inicial e continuada e mobilização dos professores para a busca de informações. No segundo, formas de valorização no campo da remuneração e do reconhecimento.

\section{Dimensão 3: gestão democrática e participação da comunidade escolar}

\section{O estudo confirmou a importância da participação como} processo constitutivo da democracia. Portanto, boas práticas de participação ampliam e qualificam a gestão democrática da escola. Nas escolas analisadas, foram identificados processos diferenciados e criativos de participação. 0 maior reflexo na aprendizagem é decorrente do aprimoramento da interlocução da gestão da escola com seus atores e da escola com interlocutores externos, como os órgãos de gestão municipal ou estadual da educação, e de outras políticas e programas de interesse da comunidade escolar, como os da assistência social, saúde, esportes, cultura.

Mais do que a existência de espaços de participação - como reuniões, colegiados, informativos eficientes o estudo verificou o incentivo e o exercício dessa participação, concretizada em conselhos escolares atuantes e presentes na vida da escola, no envolvimento ativo das famílias e dos alunos nos processos de decisão e acompanhamento da gestão escolar.

\section{Dimensão 4: alunos e alunas atuantes no dia-a-dia da escola}

As práticas apontadas nas escolas, envolvendo a participação de alunos, extrapolam os limites do simbólico quando as crianças compartilham ações concebidas, planejadas e realizadas por adultos - demonstrando o protagonismo e a importância das ações dos estudantes.

Mais do que um direito, a participação de meninos e meninas é uma condição essencial para o desenvolvimento de práticas pedagógicas construtoras de aprendizagens. Eles e elas podem e devem ser protagonistas e sujeitos ativos no ambiente social e comunitário, no ambiente escolar e na gestão da escola.
Nas escolas analisadas, muitas foram as formas de participação de alunos em atividades pedagógicas, como o apoio ao reforço escolar, a elaboração de jornais-murais, a produção da rádio-escola. Grêmios atuantes, com presença ativa e efetiva na escola, também foram encontrados.

\section{Dimensão 5: as parcerias externas}

A idéia de parcerias externas vem da compreensão de que a escola, sozinha, não é capaz de garantir a totalidade dos direitos de crianças e adolescentes. A garantia do direito à vida, à saúde, à liberdade, à convivência familiar e comunitária é resultado da ação de inúmeros organismos, governamentais ou não, das esferas públicas e privadas. A parceria dessas instituições com a escola, além de cooperar para o fortalecimento da própria instituição, contribui efetivamente para a garantia de alguns desses direitos, principalmente, o de aprender.

As escolas analisadas exercitam ricas experiências de parcerias com as instituições da comunidade, do município e até mesmo regionais ou nacionais. Os parceiros têm perfis diferenciados, são do setor empresarial (bancos, empresas de comunicação ou pequenos comerciantes), outras escolas, fundações, ONGs, universidades, sindicatos e associações comunitárias ou de moradores.

A maioria delas apóia projetos realizados pelas próprias escolas, como laboratórios de informática, programas de empreendedorismo e segurança no trânsito, combate à violência, apoio a famílias, preservação ambiental e atividades artísticas.

Além de viabilizar projetos, elas criam importantes espaços de mobilização social pela qualidade na educação.

\section{Aprova Brasil: ponto de partida para...}

Mais do que ponto de chegada, o Aprova Brasil é ponto de partida para compreender e disseminar as condições e o potencial de aprendizagem nas escolas públicas brasileiras. 0 estudo deixou questões em aberto, assim como novas possibilidades de estudos e pesquisas.

Alguns aspectos - como a importância do clima da escola, o ambiente escolar e as relações entre as pessoas - foram citados muitas vezes como fatores que estabelecem boas condições para a aprendiza- 


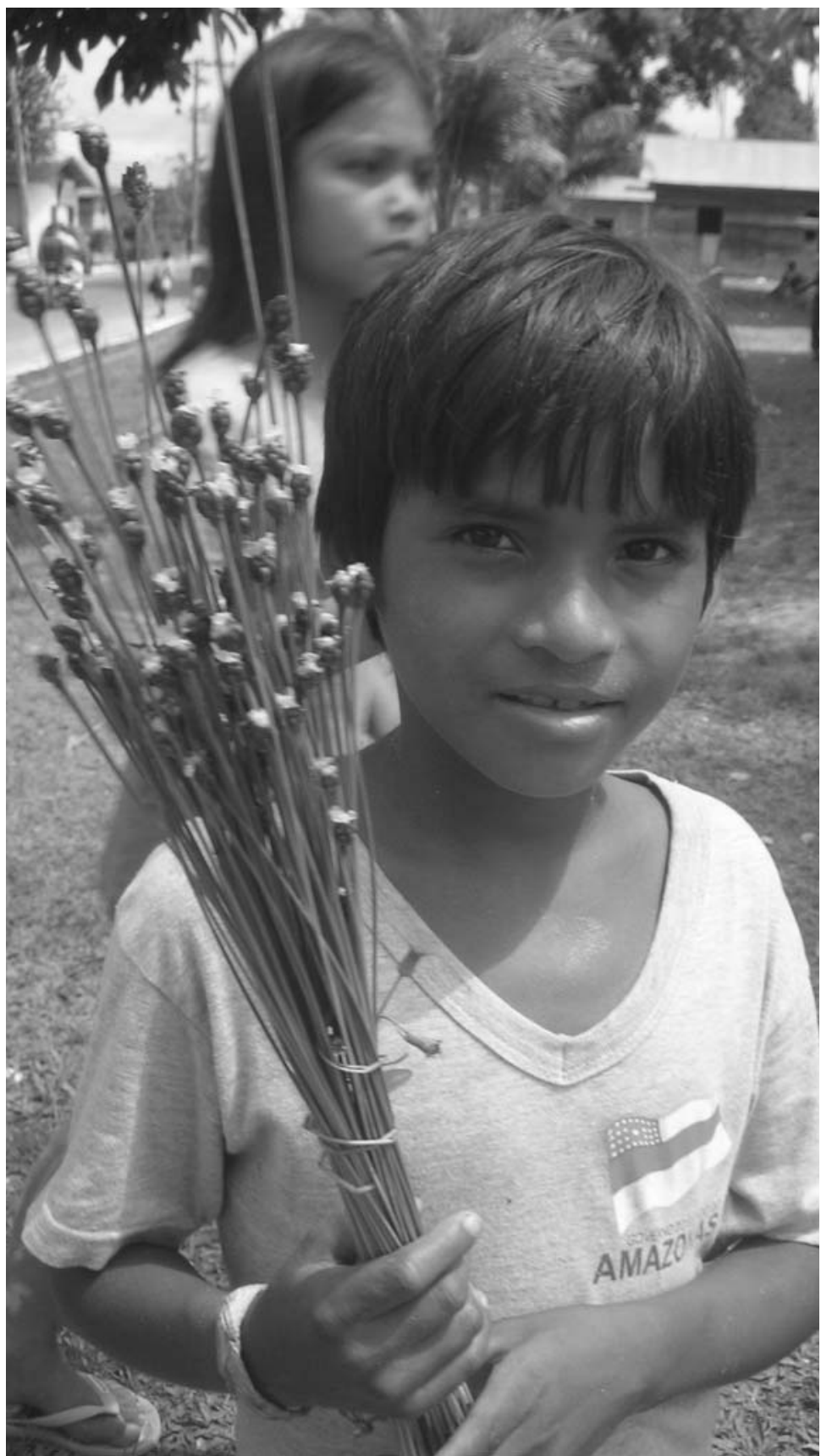

gem. Há também um novo olhar sobre a organização da escola, disciplina e normas de convivência, percebidas mais como elementos importantes para o bom funcionamento e para os resultados atingidos pelas instituições e menos como formas de coerção ou impeditivas da participação. Um outro campo de observação aberto pela pesquisa é o das relações entre escolas e sistemas ou redes e seus organismos e modelos de gestão.

O estudo não teve o objetivo de recolher ou sistematizar as dificuldades que as escolas enfrentam para desenvolver suas práticas. No entanto, essas dificuldades foram citadas pelos participantes da pesquisa e afetam diferentes áreas e momentos da vida da escola, por exemplo: as condições de infra-estrutura e a disponibilidade de espaços, equipamentos e materiais; o isolamento entre escolas da mesma rede ou do território do município; as demandas que as diferentes esferas do poder público exigem da escola; a expectativa e as dificuldades na relação com famílias; a distância e o descrédito da comunidade em relação à escola.

Voltando ao conceito inicial, de corpo e alma da escola, verificou-se que, embora sejam o lado mais visível, os aspectos materiais da escola - infra-estrutura, equipamentos, espaços - são mais eficientes para impulsionar a aprendizagem quando estão integrados, como meios, a projetos e atividades pedagógicas consistentes, concebidos e realizados pelos atores da própria escola.

O desafio que o Unicef e o MEC enfrentam, assim como todos os parceiros e instituições comprometidas com a boa qualidade da educação, é disseminar as experiências e práticas dessas 33 escolas, fazendo, do Aprova Brasil, um impulso mobilizador que inspire novas práticas e experiências em escolas públicas brasileiras.

O objetivo central da caminhada da boa qualidade da educação pública no país deve ser o de garantir, como finalidade essencial da escola, o direito de aprender para todas e cada uma das crianças e dos jovens brasileiros. 0 foco no direito de aprender pode reposicionar e dar novo significado à dimensão material e às possibilidades geradas pelas condições objetivas e subjetivas do fazer escolar.

\section{Notas}

O texto da publicação está disponível, na íntegra, em formato pdf, no sítio: 〈http://www.unicef.org/brazil/finalaprovabrz.pdf 〉.

2 Mais informações sobre a Prova Brasil podem ser obtidas no sítio: 〈http:// www.inep.gov.br/basica/saeb/anresc.htm〉.

3 Nos 155 países onde o Unicef atua, suas ações se realizam por meio de Programas de Cooperação, cada um com duração de cinco anos. Estes Programas de Cooperação são preparados com a participação do Governo e de diferentes atores da sociedade civil, incluindo as próprias crianças e os adolescentes. 0 documento do Programa de País (PP), resultado desse processo de discussão, é assinado com os governos nacionais e serve de aval para a atuação do Unicef no país.

4 IBGE/PNAD, 2004 e MEC/INEP Censo Escolar, 2005. 5 IBGE/PNAD, 2004 e MEC/INEP Censo Escolar, 2005.

6 Foram visitadas 36 escolas, mas, em três delas, foram identificadas práticas de seleção para ingresso. Como isso estabeleceria um diferencial importante em relação às outras escolas, essas três não foram incluídas nos resultados do estudo.

7 Trecho do poema Amor bastante, de Paulo Leminsky.

8 BOFF, Leonardo. A águia e a galinha: metáfora da condição humana. Petrópolis: Vozes, 1999.

9 MEC/INEP, Unicef, PNUD e Ação Educativa. Indicadores de Qualidade na Educação. São Paulo, 2004. 